\title{
CHLOROPLAST DNA SYSTEMATICS OF LILIOID MONOCOTS: RESOURCES, FEASIBILITY, AND AN EXAMPLE FROM THE ORCHIDACEAE ${ }^{1}$
}

\author{
Mark W. Chase ${ }^{2}$ and JefFrey D. Palmer ${ }^{3}$ \\ Department of Biology, University of Michigan, Ann Arbor, Michigan 48109-1048
}

\begin{abstract}
A B S T R A C T
Although chloroplast DNA (cpDNA) analysis has been widely and successfully applied to systematic and evolutionary problems in a wide variety of dicots, its use in monocots has thus far been limited to the Poaceae. The cpDNAs of grasses are significantly altered in arrangement relative to the genomes of most vascular plants, and thus the available clone banks of grasses are not particularly useful in studying variation in the cpDNA of other monocots. In this report, we present mapping studies demonstrating that cpDNAs of four lilioid monocots (Allium cepa, Alliaceae; Asparagus sprengeri, Asparagaceae; Narcissus $\times$ hybridus, Amaryllidaceae; and Oncidium excavatum, Orchidaceae), which, while varying in size over as much as 18 kilobase pairs, conform to the genome arrangement typical of most vascular plants. A nearly complete $(99.2 \%)$ clone bank was constructed from restriction fragments of the chloroplast genome of Oncidium excavatum; this bank should be useful in cpDNA analysis among the monocots and is available upon request. As an example of the utility of filter hybridization using this clone bank to detect systematically useful variation, we present a Wagner parsimony analysis of restriction site data from the controversial genus Trichocentrum and several sections of Oncidium, popularly known as the "mule ear" and "rat tail oncidiums." Because of their vastly different floral morphology, the species of Trichocentrum have never been placed in Oncidium, although several authors have recently suggested a close relationship to this vegetatively modified group. The analysis of cpDNA presented here supports this affinity; in fact, it places Trichocentrum as a derivative of the mule ear oncidiums.
\end{abstract}

AMONG THE DICOTS, systematic studies of chloroplast DNA (cpDNA) variation are relatively common and have been applied to a wide variety of species at several taxonomic levels (see review in Palmer et al., 1988a). As is true of systematic studies of monocots in general, the principal focus of molecular studies in the monocots has been the Poaceae (Tsunewaki and Ogihara, 1983; Enomoto, Ogihara, and Tsunewaki, 1985; Doebley, Renfroe, and Blanton, 1987; Lehvaslaiho, Saura, and Lokki, 1987; Hilu, 1988). The chloroplast genome in the grasses differs significantly from those found thus far in the dicots in the possession of at

\footnotetext{
' Received for publication 20 January 1989; revision accepted 25 May 1989.

We wish to acknowledge the support of a National Science Foundation Fellowship in Environmental Biology, BSR-8600179, to MWC. We are also grateful for permission to remove leaves and flowers from the orchid collections of Alexis and Ted Linder (Great Lakes Orchids) and Ron Cnesinski (Taylor Orchids). Requests for the orchid cpDNA clone bank described here should be directed to MWC. We are grateful to William F. Thompson for providing laboratory facilities for the portion of the work performed in 1982-1983.

${ }^{2}$ Current address: Department of Biology, University of North Carolina, Chapel Hill, NC 27599-3280.

${ }^{3}$ Current address: Department of Biology, Indiana University, Bloomington, IN 47405.
}

least three large inversions (Palmer, 1985; Howe et al., 1988). Clone banks constructed from these highly rearranged genomes are of limited use in mapping studies of other vascular plants, and thus far the sources of $c p D N A$ probes in filter hybridizations have been limited to those of dicots, such as spinach, petunia, and tobacco, that have the consensus arrangement for flowering plants. The chloroplast genome of Spirodela oligorhiza (Araceae) has been mapped (de Heij et al., 1983) and was found to be colinear with the consensus vascular plant arrangement, although it was 30 kilobase pairs (kb) larger than that of Petunia.

In this study we focused on four lilioid monocots: Allium cepa (Alliaceae), Asparagus sprengeri (Asparagaceae), Narcissus $\times$ hybridus (Amaryllidaceae), and Oncidium excavatum (Orchidaceae). Physical and gene mapping studies reveal that, unlike the grasses, the genome arrangement of these monocots is typical of that of most land plants.

Furthermore, we have constructed a clone bank of restriction fragments of one of these species, Oncidium excavatum and have used this bank in filter hybridizations to discover systematically useful variation in the cpDNA of other orchids. As an example of the utility of this approach in gathering useful new in- 
TABLE 1. Sources of DNA from species in the Oncidinae (vouchered by flowers in FAA in the first author's private collection)

\begin{tabular}{llc}
\hline \multicolumn{1}{c}{ Species } & \multicolumn{1}{c}{ Origin" } & voucher number \\
\hline 1. Oncidium excavatum & Cajamarca, Peru (GLO) & 83427 \\
2. Rossioglossum schlieperianum & Chiriquí, Panama (GLO) & 83449 \\
3. Oncidium ampliatum & Chiriqui, Panama (MWC) & 84104 \\
4. Psychopsis sanderae & Peru (TO) & 86126 \\
5. Oncidium jonesianum & Paraguay (TO) & 86118 \\
6. Oncidium ascendens & Chiapas, Mexico (MWC) & 82109 \\
7. Oncidium flavovirens & Colima, Mexico (MWC) & 83109 \\
8. Oncidium splendidum & Guatemala (UMBG) & 84552 \\
9. Oncidium bicallosum & Chiapas, Mexico (MWC) & 83387 \\
10. Trichocentrum panduratum & Peru (TO) & 86179 \\
11. Trichocentrum tigrinum & Peru (RO) & 83439 \\
12. Oncidium pulvinatum & Brazil (GLO) & 82228 \\
13. Oncidium hians & Brazil (SBOE) & 86134 \\
\hline
\end{tabular}

a GLO $=$ Great Lakes Orchids; MWC $=$ Mark W. Chase, field collected; TO = Taylor Orchids; UMBG $=$ Matthaei Botanical Garden, University of Michigan; RO = R. J. Rands Orchids; SBOE = Santa Barbara Orchid Estate.

formation that differentiates opposing hypotheses about phylogenetic relationships, we present an analysis of cpDNA variation among a controversial group of orchids. Some members of the oncidioid orchids (subtribe Oncidiinae) display a series of vegetative modifications (succulence) that have earned for them the common names of "mule ear" and "rat tail oncidiums." Members of the genus Trichocentrum also exhibit the "mule ear" condition but have a floral morphology that is radically different from any species on Oncidium. Dressler and Williams (1982) suggested that Trichocentrum is closely related to these vegetatively modified oncidiums. Others (Wirth, 1964; Chase, 1986) viewed the exceptionally distinctive floral morphology of Trichocentrum as support for a view that the similar vegetative features are due to parallelism. A series of other members of Oncidium have less extreme vegetative features that also suggest a relationship to the mule ear group. We examined restriction site variation in cpDNA, as detected by filter hybridization, among these species in order to test the conflicting ideas of their phylogenetic relationships.

MATERIALS AND METHODS-CpDNAs of $A l$ lium cepa, Asparagus sprengeri, Narcissus $\times$ hybridus and Oncidium excavatum were isolated by the sucrose gradient technique (Palmer, 1986). For all other taxa, total cellular DNAs were isolated by the modified CTAB method of Doyle and Doyle (1987). Most of the members of the mule ear oncidium group are succulent, and the standard method of isolation of total cellular DNA did not work well or at all. This problem was remedied by using a $3 \times$ CTAB buffer rather than the standard $2 \times$.
Sources of material of each orchid species are listed in Table 1. All DNAs were further purified by means of cesium chloride-ethidium bromide gradients.

Restriction endonuclease digests, electrophoresis, transfer to nylon filters, labelling of recombinant plasmids, filter hybridizations, and autoradiography were carried out according to Palmer (1986). Washing of the filters was done under the following conditions: two washes of 15 minutes at room temperature, followed by two washes for $30-60 \mathrm{~min}$ at 65 $\mathrm{C}$, with a $2 \times$ SSC, $0.5 \%$ SDS wash buffer. After a round of hybridization, the probes were stripped from the filters by $3-4$ washes of boiling $0.1 \times$ SSC. These filters (Zetabind, AMF Cuno) went through over 30 rounds of hybridizations and were still in usable condition.

A restriction site map for 6 enzymes was constructed for $O$. excavatum (Fig. 1) using the mapping strategy of Palmer(1986). The cpDNA probes for this mapping were the clone bank of Lactuca sativa (Jansen and Palmer, 1987). For the region in which $L$. sativa has a $22 \mathrm{~kb}$ inversion, we substituted the three uninverted Petunia $\times$ hybrida clones (Palmer et al., 1983). Once this restriction fragment map was completed, gene probes from tobacco, spinach, and pea were hybridized to the same filters to identify their locations in this genome (for probe descriptions, see Jansen and Palmer, 1987). The representatives of three other lilioid monocots, Allium cepa, Asparagus sprengeri, and Narcissus $\times$ hybridus, were mapped for two restriction enzymes, PvuII and SacI, using the cloned genome of Vigna radiata (mung bean; Palmer and Thompson, 1981) as the source of cpDNA probes. (At the time this mapping was performed, more appropriate clone banks [i.e., 


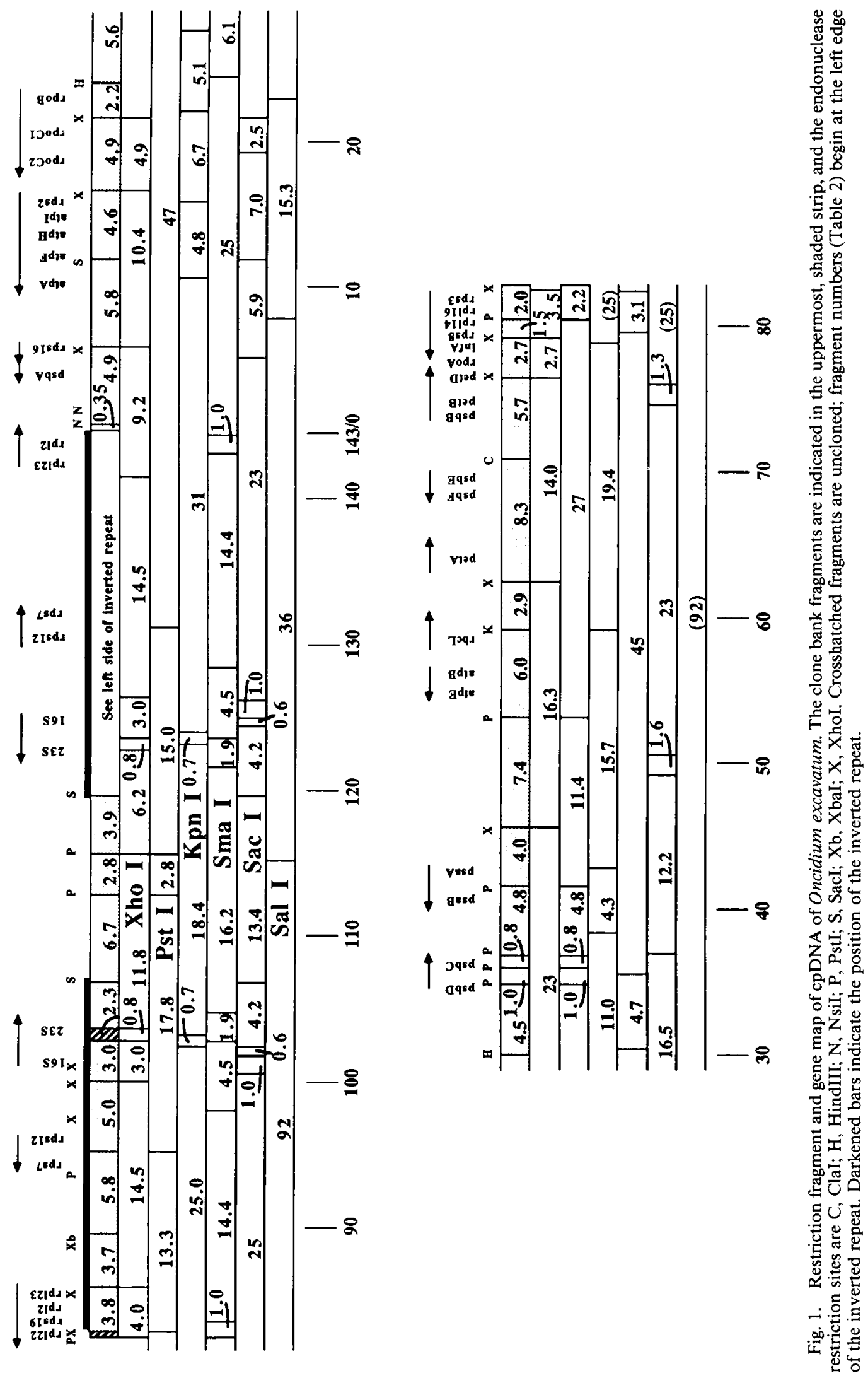




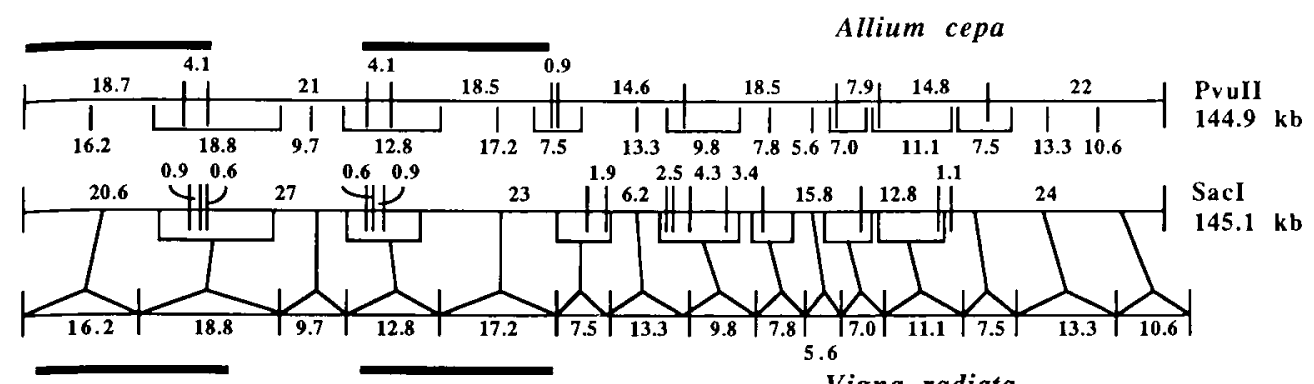

Vigna radiata

\section{Asparagus sprengeri}
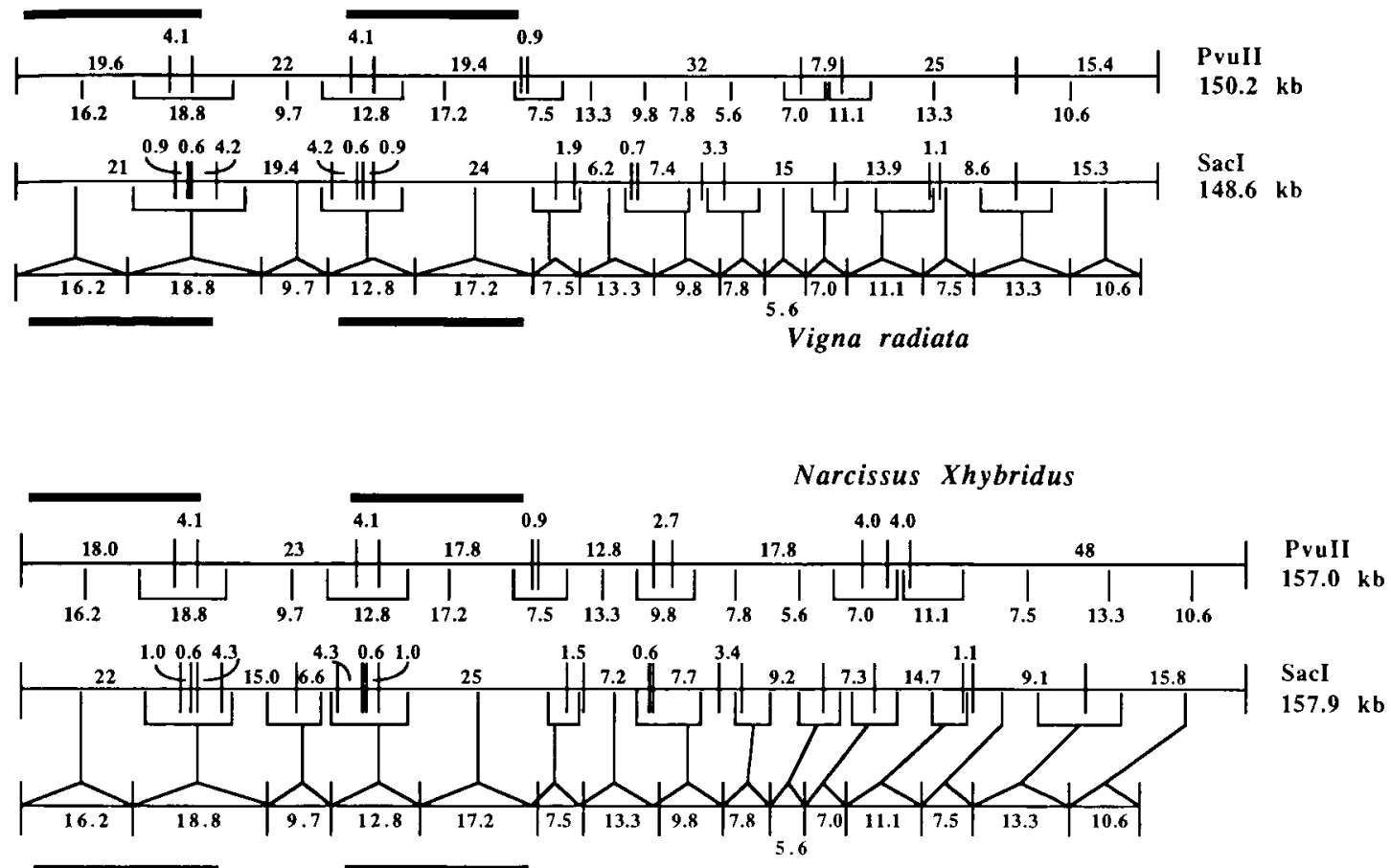

Vigna radiata

Fig. 2. Restriction fragment maps of Allium, Asparagus, and Narcissus for the endonucleases PvuII and SacI, with the relative position of the mung bean clones used in the filter hybridizations. Lines from the mung bean clones to fragments in the other species indicate fragments hybridizing to the mung bean sequences. The mung bean map is drawn with the position of a $50 \mathrm{~kb}$, legume-specific inversion reversed, in order to approximate the arrangement typical of most vascular plants (i.e., the $7.5 \mathrm{~kb}$ and $13.3 \mathrm{~kb}$ fragments, which contain the ends of the inversion, are shown twice). Position of the inverted repeat is indicated by the dark bars above each map (end points have not been accurately determined and are only approximations).

ones that did not contain inversions] were unavailable.) In Fig. 2, we have corrected for the $50 \mathrm{~kb}$ inversion found in Vigna radiata, while a second, larger inversion that affects the whole large single copy region (Palmer, Osorio, and Thompson, 1988b) does not require compensation.

The chloroplast genome of Oncidium excavatum was cloned using a combination of the restriction enzymes PstI and Xhol, which produced 23 fragments from $0.2-14.0 \mathrm{~kb}$. Initial cloning was into pIC20H (Marsh, Erfle, and Wilkes, 1984) by the shotgun method. Later cloning was into Bluescript sk + (Stratagene, Inc.) by gel-isolating fragments from digests separated in low melt agarose. Fragments longer than $8.5 \mathrm{~kb}$ were subcloned by digesting the larger fragments with an appropriate set of en- 
TABLE 2. Clones and subclones of Oncidium excavatum

\begin{tabular}{|c|c|c|c|}
\hline Fragment number & Size & Enzymes & Vector \\
\hline 1 & $3.8 \mathrm{~kb}$ & PstI-XhoI & pIC $20 \mathrm{H}$ \\
\hline 2 & $9.5 \mathrm{~kb}$ & Xhol-PstI & pIC $20 \mathrm{H}$ \\
\hline a. & $3.7 \mathrm{~kb}$ & Xhol-Xbal & BS sk+ \\
\hline b. & $5.8 \mathrm{~kb}$ & Xbal-PstI & BS sk+ \\
\hline 3 & $5.0 \mathrm{~kb}$ & PstI-XhoI & $\mathrm{pIC} 20 \mathrm{H}$ \\
\hline 4 & $3.0 \mathrm{~kb}$ & Xhol-PstI & plC2OH \\
\hline 5 (uncloned) & $0.8 \mathrm{~kb}$ & XhoI-Xhol & \\
\hline 6 & $9.1 \mathrm{~kb}$ & XhoI-PstI & pIC20H \\
\hline a. & $2.3 \mathrm{~kb}$ & XhoI-SacI & BS sk+ \\
\hline b. & $6.7 \mathrm{~kb}$ & SacI-PstI & pIC $20 \mathrm{H}$ \\
\hline 7 & $2.8 \mathrm{~kb}$ & PstI-PstI & BS sk+ \\
\hline $8 \dagger$ & $6.3 \mathrm{~kb}$ & PstI-Xhol & pIC $20 \mathrm{H}$ \\
\hline a. & $3.9 \mathrm{~kb}$ & PstI-SacI & pIC2OH \\
\hline $9 \dagger$ & $9.4 \mathrm{~kb}$ & Xhol-Xhol & BS sk+ \\
\hline a.* & $0.35 \mathrm{~kb}$ & Nsil-NsiI & BS sk+ \\
\hline b.* & $4.9 \mathrm{~kb}$ & NsiI-PstI & BS sk+ \\
\hline 10 & $10.2 \mathrm{~kb}$ & Xhol-Xhol & BS sk+ \\
\hline a. & $5.7 \mathrm{~kb}$ & XhoI-SacI & $\mathrm{BS}$ sk+ \\
\hline b. & $4.5 \mathrm{~kb}$ & Sacl-XhoI & $\mathrm{BS}$ sk + \\
\hline 11 & $4.9 \mathrm{~kb}$ & XhoI-Xhol & pIC2OH \\
\hline 12 & $12.3 \mathrm{~kb}$ & XhoI-PstI & BS sk+ \\
\hline a. & $2.2 \mathrm{~kb}$ & XhoI-HindIII & BS sk+ \\
\hline b. & $5.6 \mathrm{~kb}$ & HindIII-HindIII & $\mathrm{BS}$ sk + \\
\hline c. & $4.5 \mathrm{~kb}$ & HindIII-PstI & BS sk + \\
\hline 13 & $1.0 \mathrm{~kb}$ & PstI-PstI & pIC $20 \mathrm{H}$ \\
\hline 14 & $0.8 \mathrm{~kb}$ & PstI-PstI & pIC $20 \mathrm{H}$ \\
\hline 15 & $4.8 \mathrm{~kb}$ & PstI-PstI & pIC $20 \mathrm{H}$ \\
\hline 16 & $4.0 \mathrm{~kb}$ & PstI-XhoI & pIC $20 \mathrm{H}$ \\
\hline 17 & $7.4 \mathrm{~kb}$ & Xhol-PstI & pIC $20 \mathrm{H}$ \\
\hline 18 & $8.9 \mathrm{~kb}$ & PstI-XhoI & pIC $20 \mathrm{H}$ \\
\hline a. & $6.0 \mathrm{~kb}$ & Pstl-KpnI & BS sk+ \\
\hline b. & $2.9 \mathrm{~kb}$ & KpnI-Xhol & pIC20H \\
\hline 19 & $14.0 \mathrm{~kb}$ & Xhol-Xhol & BS sk+ \\
\hline a. & $8.3 \mathrm{~kb}$ & XhoI-ClaI & BS sk+ \\
\hline b. & $5.7 \mathrm{~kb}$ & ClaI-Xhol & BS sk+ \\
\hline 20 & $2.7 \mathrm{~kb}$ & Xhol-Xhol & BS sk+ \\
\hline 21 & $1.5 \mathrm{~kb}$ & XhoI-PstI & pIC20H \\
\hline 22 & $2.0 \mathrm{~kb}$ & PstI-XhoI & $\mathrm{pIC} 20 \mathrm{H}$ \\
\hline 23 (uncloned) & $0.2 \mathrm{~kb}$ & XhoI-PstI & \\
\hline
\end{tabular}

$\dagger$ Only the single copy portions of these cloned fragments have been subcloned.

* Hybrid cloning sites.

zymes, separating them in low melt agarose, cutting the fragments out, and ligating them with the appropriately cut vector. In this way, a clone bank with a total of 30 cloned fragments was produced (Table 2 ). The $O$. excavatum clone bank was then used to map restriction sites for ten enzymes that cut a typical chloroplast genome 35-80 times each. Phylogenetic analysis was performed using the Wagner parsimony programs, PAUP (D. Swofford; including the branch and bound and strict consensus tree options) and PHYLIP (Felsenstein, 1985; including the bootstrap option). Sequence divergence was calculated for the most closely and distantly related species pairs using equations 9 and 10 of Nei and Li (1979).

RESULTS-Genome size and structure-The linearized cpDNA maps for Allium, Aspara- gus, and Narcissus are shown in Fig. 2. Large inversions, such as have been found in the grasses, are absent from these monocot genomes. At this level of analysis, they are colinear with that of the typical, unrearranged dicot genome, such as tobacco or spinach, and with that of Oncidium (Fig. 1). The major difference among these genomes is size: Oncidium is $143 \mathrm{~kb}$ long, Allium, $145 \mathrm{~kb}$; Asparagus, 149 $\mathrm{kb}$; and Narcissus, $157 \mathrm{~kb}$. The major structural feature of these genomes is a large inverted repeat, which we estimate in Oncidium to have a maximum and minimum sizes of 25.6 and $24.4 \mathrm{~kb}$, respectively. The smaller size of this genome appears to be the product of major reduction in a few regions rather than uniform reduction throughout the genome. For example, an $18.8 \mathrm{~kb}$ SacI fragment from lettuce (containing the entire small single copy region) hy- 

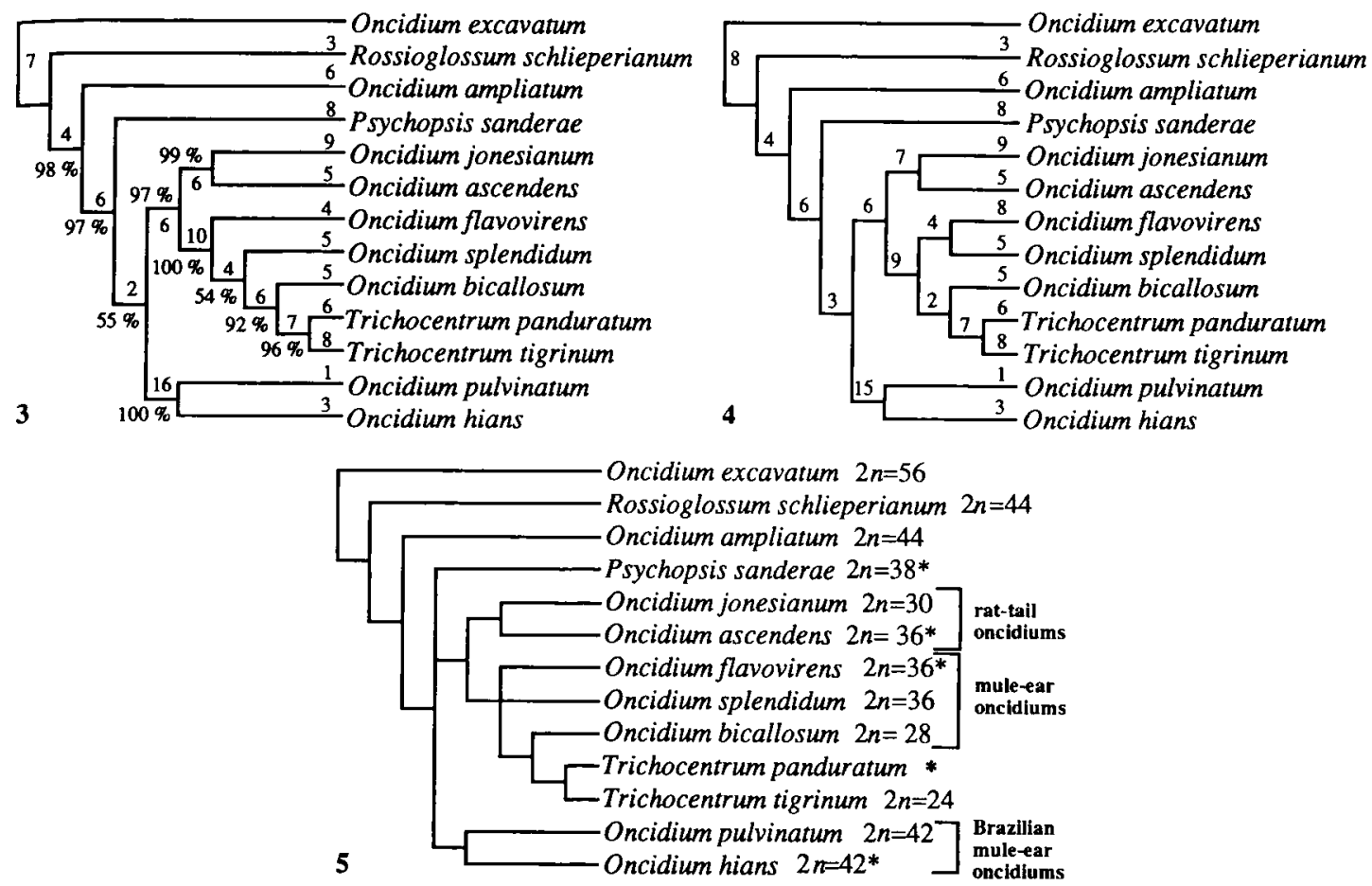

Fig. 3-5. Wagner parsimony trees of the vegetatively modified members of Oncidium, Psychopsis, and Trichocentrum, rooted with Oncidium excavatum and Rossioglossum. The numbers at each node and taxon are the number of site mutations that define each lineage. 3. One of two equally parsimonious trees found by both PAUP and PHYLIP. These two trees each have 79 steps and consistency indices of 0.92 . The bootstrap option of PHYLIP was used to establish a measure of statistical significance for each monophyletic lineage, and this is expressed as a percentage. 4. The alternate, equally most parsimonious tree found by PAUP and PHYLIP. The only difference between this tree and that in Fig. 3 is the relationship of $O$. splendidum and $O$. flavovirens to each other and the clade to which they are sister taxa. 5. Strict consensus tree (from PAUP), to which chromosome numbers (Tanaka and Kamemoto, 1984) have been added. Taxa marked with an asterisk have not been counted; in cases in which a closely related species has been counted, those chromosome numbers have been presented.

bridizes to only a 13.4 SacI fragment in the orchid. Fine structure mapping experiments suggest that these SacI sites are homologous, which means that in the small single copy region alone the orchid is $5.4 \mathrm{~kb}$ shorter than lettuce. Many of the SacI and PvuII sites in all four genomes may in fact be conserved; if this is indeed true then it appears that some regions of these genomes are expanding while others are shrinking and not always in the same direction as the genome is changing as a whole. For example, if the PvuII sites that produce the $4.1 \mathrm{~kb}$ and $0.9 \mathrm{~kb}$ fragments flanking a large fragment comprising most of the inverted repeat are homologous (Fig. 2), then Narcissus, with the largest genome, is the most condensed for this fragment. Further studies are needed to determine whether such size differences in the small single copy region are due primarily to shorter intergenic spacers, fewer and shorter introns, or fewer genes.

Clone bank composition - Our desire to undertake further experiments in the lilioid monocots, particularly the orchids, led us to clone an orchid chloroplast genome. All of the 21 original orchid clones that exceeded $8.5 \mathrm{~kb}$ in length were subcloned so that the clone bank now consists of 30 fragments. These clones represent $98.7 \%$ of the $O$. excavatum genome ( $99.2 \%$ of the sequence diversity). Fragments that extend over the boundaries of the inverted repeat, clones 6,8 , and 9 , were subcloned using sites near the edge of the inverted repeat in order to generate more specific probes that will produce simpler and more readily interpretable hybridization patterns.

Sequence divergence-Sequence divergence values (Nei and Li, 1979) were calculated for the most distantly and most closely related species pairs among these 13 orchid species (Fig. 3). The most closely related pair, $O$. hians and $O$. pulvinatum, and the most distantly related, $O$. excavatum and $T$. tigrinum, diverged by $0.14 \%$ and $2.77 \%$, respectively, which are typical of values reported for intrageneric studies (Palmer and Zamir, 1982; Palmer et al., 
TABLE 3. Chloroplast DNA restriction site mutations for the nine enzymes used in phylogenetic analyses of 13 species in the Oncidiinae (Table 1). Only the mutations that group two or more species (synapomorphies) are listed. Map coordinates are cited to the nearest $0.5 \mathrm{~kb}$ (see Fig. 2) for each mutation, which are listed with the ancestral state (see Methods) first and the derived state second. Taxa sharing a given mutation are numbered as in Table 1

\begin{tabular}{|c|c|c|c|}
\hline Enzyme & Region & Mutation & Taxa \\
\hline b1. A & 96.0 & $6.6 \rightarrow 5.2+1.3$ & $4,7,8$ \\
\hline b2. A & 98.5 & $0.9+1.2 \rightarrow 2.1$ & 5,6 \\
\hline 3. $\mathrm{A}$ & 10.5 & $0.3+0.7 \rightarrow 1.0^{*}$ & $4,12,13$ \\
\hline 4. $\mathrm{A}$ & 50.5 & $2.2 \rightarrow 1.6+0.6^{*}$ & $2-13$ \\
\hline 5. $\mathrm{A}$ & 53.0 & $1.6 \rightarrow 1.1+0.5^{*}$ & 5,6 \\
\hline 6. A & 70.5 & $2.4+3.4 \rightarrow 5.8$ & $2-13$ \\
\hline 7. $\mathrm{A}$ & 80.0 & $9.6 \rightarrow 6.3+2.3$ & $2-13$ \\
\hline 8. A & 78.5 & $9.4 \rightarrow 8.3+1.1$ & $2-13$ \\
\hline 9. B & 97.0 & $18.0+2.0 \rightarrow 20.0$ & $8-11$ \\
\hline 10. B & 33.5 & $10.9 \rightarrow 6.9+4.0$ & $4-13$ \\
\hline 11. B & 75.0 & $4.4+2.6 \rightarrow 7.0$ & $5-11$ \\
\hline 12. C & 95.0 & $15.2-11.4+3.8$ & 12,13 \\
\hline 13. C & 78.0 & $4.3+1.0 \rightarrow 5.3^{*}$ & 10,11 \\
\hline 14. $\mathrm{C}$ & 2.0 & $4.7+0.8 \rightarrow 5.5$ & $5-13$ \\
\hline 15. C & 11.5 & $3.8+9.2 \rightarrow 13.0$ & $5-11$ \\
\hline 16. $\mathrm{C}$ & 26.0 & $4.0-2.3+1.7$ & 5,6 \\
\hline 17. $\mathrm{C}$ & 23.5 & $4.0+1.1 \rightarrow 5.1$ & 12,13 \\
\hline 18. C & 22.5 & $1.1+5.1 \rightarrow 6.2^{*}$ & 12,13 \\
\hline 19. C & 23.5 & $5.1 \rightarrow 4.0+1.1$ & $7-11$ \\
\hline 20. C & 44.5 & $16.0+3.1 \rightarrow 19.1$ & 12,13 \\
\hline b21. C & 47.5 & $3.1+9.5-12.6$ & $8-10$ \\
\hline 22. $\mathrm{C}$ & 52.5 & $9.5 \rightarrow 4.3+5.2$ & 12,13 \\
\hline 23. $\mathrm{C}$ & 68.5 & $4.2+2.6 \rightarrow 6.8^{*}$ & 10,11 \\
\hline 24. C & 65.0 & $4.3 \rightarrow 3.6+0.7^{*}$ & $9-11$ \\
\hline 25. C & 71.5 & $4.2 \rightarrow 2.6+1.6$ & $2-13$ \\
\hline 26. $\mathrm{C}$ & 76.0 & $2.7+1.0 \rightarrow 3.7^{*}$ & 10,11 \\
\hline b27. D & 94.0 & $11.8+6.1 \rightarrow 17.9$ & $4,7,8$ \\
\hline 28. D & 0.5 & $11.8 \rightarrow 9.8+2.0$ & 10,11 \\
\hline b29. D & 49.0 & $5.6+10.9 \rightarrow 16.5$ & $8-10,12,13$ \\
\hline 30. E & 93.0 & $1.6 \rightarrow 1.2+0.4$ & $3-13$ \\
\hline 31. E & 92.5 & $1.2 \rightarrow 0.8+0.6$ & 7,8 \\
\hline b32. $\mathrm{E}$ & 96.5 & $1.5 \rightarrow 1.1+0.4^{*}$ & $4,7,8$ \\
\hline 33. $\mathrm{E}$ & 10.5 & $12.3 \rightarrow 8.5+3.8$ & $5-11$ \\
\hline 34. $\bar{E}$ & 16.0 & $2.4 \rightarrow 1.4+1.0^{*}$ & $5-13$ \\
\hline 35. E & 40.5 & $7.0+3.5 \rightarrow 10.5$ & 12,13 \\
\hline 36. E & 47.0 & $8.7 \rightarrow 6.6+2.1$ & $4-11$ \\
\hline 37. $\mathrm{E}$ & 45.5 & $5.2 \rightarrow 3.6+1.6$ & 12,13 \\
\hline 38. $\mathrm{E}$ & 78.5 & $5.2+2.0 \rightarrow 7.2$ & $4-13$ \\
\hline 39. $F$ & 92.0 & $1.6+1.1 \rightarrow 2.7$ & $2-13$ \\
\hline 40. F & 100.0 & $3.5 \rightarrow 3.1+0.4^{*}$ & $8-11$ \\
\hline 41. $\mathrm{F}$ & 5.5 & $2.6+4.2 \rightarrow 6.8$ & $3-11$ \\
\hline 42. $\mathrm{F}$ & 64.0 & $14.0 \rightarrow 3.5+10.5$ & $2-13$ \\
\hline 43. $\mathrm{G}$ & 83.0 & $5.1 \rightarrow 1.5+3.6$ & 12,13 \\
\hline 44. $\mathrm{G}$ & 91.5 & $2.4 \rightarrow 1.9+0.5^{*}$ & $2-13$ \\
\hline 45. $\mathrm{G}$ & 36.5 & $2.9 \rightarrow 1.1+1.8^{*}$ & 10,11 \\
\hline 46. $\mathrm{G}$ & 52.0 & $1.6 \rightarrow 1.1+0.5^{*}$ & 5,6 \\
\hline 47. $\mathrm{G}$ & 58.0 & $7.4 \rightarrow 3.1+4.3$ & 10,11 \\
\hline 48. $\mathrm{G}$ & 59.5 & $7.4 \rightarrow 6.1+1.3$ & 12,13 \\
\hline 49. $\mathrm{G}$ & 36.5 & $1.1+1.8 \rightarrow 2.9$ & 10,11 \\
\hline 50. G & 46.0 & $1.1+1.2 \rightarrow 2.3$ & $7-11$ \\
\hline 51. H & 4.0 & $2.0 \rightarrow 1.5+0.5^{*}$ & $5-11$ \\
\hline 52. $\mathrm{H}$ & 11.0 & $12.2+2.0 \rightarrow 14.2$ & $7-11$ \\
\hline 53. $\mathrm{H}$ & 14.0 & $12.2 \rightarrow 10.2+2.0$ & $3-11$ \\
\hline 54. $\mathrm{H}$ & 12.5 & $10.2 \rightarrow 7.8+2.4$ & 12,13 \\
\hline b55. H & 19.0 & $12.2 \rightarrow 9.8+2.4$ & $3-6,12,13$ \\
\hline 56. $\mathrm{H}$ & 23.0 & $12.2+3.1-15.3$ & $7-11$ \\
\hline
\end{tabular}

TABLE 3. Continued

\begin{tabular}{crll}
\hline \hline Enzyme $^{*}$ & \multicolumn{1}{c}{ Region } & \multicolumn{1}{c}{ Mutation } & \multicolumn{1}{c}{ Taxa } \\
\hline 57. H & 21.5 & $12.2 \rightarrow 7.6+4.6$ & 12,13 \\
$58 . \mathrm{H}$ & 38.0 & $2.1+9.0 \rightarrow 11.1$ & $4-13$ \\
$59 . \mathrm{H}$ & 38.5 & $11.1 \rightarrow 10.5+0.5$ & 5,6 \\
$60 . \mathrm{H}$ & 40.0 & $11.1 \rightarrow 9.8+1.3$ & 12,13 \\
$61 . \mathrm{H}$ & 44.5 & $11.1 \rightarrow 5.6+5.5$ & $9-11$ \\
$62 . \mathrm{I}$ & 5.5 & $1.0+0.4 \rightarrow 2.4^{*}$ & $5-11$ \\
$63 . \mathrm{I}$ & 16.0 & $2.7+1.4 \rightarrow 4.1$ & $7-11$ \\
$64 . \mathrm{I}$ & 10.5 & $4.1+1.0 \rightarrow 5.1^{*}$ & 5,6 \\
$65 . \mathrm{I}$ & 19.0 & $2.2+2.2 \rightarrow 4.4$ & $4-13$ \\
$66 . \mathrm{I}$ & 41.0 & $7.4 \rightarrow 5.9+1.5^{*}$ & 10,11
\end{tabular}

a Enzyme abbreviations: A, BanII; B, BamHI; C, XbaI; D, HindIII; E, ClaI; F, BanI; G, BglII; H, EcoRI; I, EcoRV. Nsil was mapped but no mutated sites were discovered.

${ }^{b}$ Homoplasious site mutation relative to most parsimonious cladograms.

* Exact position uncertain because two or more fragments are unordered.

1983; Sytsma and Schaal, 1985; Sytsma and Gottlieb, 1986; Doebley et al., 1987).

Phylogenetic analyses - Three major regions of size variation were uncovered among the orchid genomes studied here. Point mutations in these regions were not utilized in this analysis unless the fragments in which point mutations were hypothesized appeared to be free of size variation. These three regions were the $13.4 \mathrm{~kb}$ small single copy region, which varied by as much as $1 \mathrm{~kb}$ between species, and the regions between coordinates $24-32$ and 48-52 (Fig. 1), which were less variable in size. Length mutations responsible for size variation were not used in phylogenetic analyses because of the nearly continuous size variation observed, which made assessments of identity and polarity impractical. Several other regions of small size variation were also detected, but these were not of significant size or distribution to affect this analysis.

Approximately 370 restriction sites were mapped for each species, and 125 site mutations were found, of which 66 were shared by two or more species (Table 3). Polarity of these mutations was determined by outgroup comparison to $O$. excavatum and Rossioglossum schlieperianum (see the second paragraph of the discussion for the reasons these two taxa were chosen). These two outgroups agreed with respect to polarity for all but the 7 or $8 \mathrm{mu}$ tations that occurred between these two species and that could not be polarized. These data were then used to construct Wagner parsimony trees with both PAUP and PHYLIP.

Two, equally parsimonious trees (Fig. 3, 4), which differ only in the relationship of two species, $O$. flavovirens and $O$. splendidum, were 
found. In Fig. 3, O. flavovirens is the sister species to a group of species that includes $O$. splendidum, while in Fig. 4 these two species together form a sister group to the same set of species that included $O$. splendidum in Fig. 3. These two trees have 79 steps and consistency indices of 0.92 ( $8 \%$ homoplasy) for all mutations and $0.84(16 \%)$ for informative ones (synapomorphies only). Four additional trees were found at 80 steps and six more at 81 steps, and these ten plus the two most parsimonious trees were used to construct the strict consensus tree (PAUP; Fig. 5). We did not use a Dollo parsimony analysis because the level of homoplasy detected was so low. Relative to the cladograms in Fig. 3 and 4, the homoplasious mutations (from Table 3 ) are of the following types: two parallel site gains $(1,27)$; one parallel site loss (32); two gain/losses $(3,55)$; and two loss/gains $(21,29)$.

The bootstrap option of PHYLIP was used to place confidence intervals (in percentage of samples in which the same placement occurred) on the monophyletic groups identified in the majority rule consensus tree (Fig. 3). One hundred samples were run, and only two nodes were found to have less than $92 \%$ confidence intervals. Not surprisingly, the weakest node was the one (54\%) at which the alternate equally parsimonious arrangement occurs. In the strict consensus tree (Fig. 5), these two weakest nodes collapse into trichotomies. These analyses demonstrate strong support for the monophyly of the vegetatively modified members of Oncidium relative to the two outgroup taxa and place genus Trichocentrum as a derivative of the mule ear oncidiums, as exemplified here by $O$. bicallosum.

Discussion - While the four lilioid monocots lack the cpDNA inversions typical of grasses and were colinear with other flowering plants lacking such inversions, they vary considerably in size. Allium, Asparagus, and Narcissus all belong to the Liliaceae sensu lato, in the order Liliales, while the Orchidaceae is placed traditionally near the Liliales in its own order, Orchidales. In size, the cpDNAs of $\mathrm{Al}$ lium and Oncidium are more similar than that of Allium is to the other members of the traditional Liliaceae, but in specific regions the orchid is quite different. We assert that it would be imprudent to try to infer anything about the systematic relationships of these four genera by comparisons of their restriction site maps. The obvious and widespread size variation, as well as the small number of restriction sites mapped, would undoubtedly be a major source of error in any such study.
While restriction site analysis is unlikely to provide the phylogenetically useful information about major groups of lilioid monocots, the approach promises to be useful within more closely related taxa, and it is in this frame of reference that the study of the vegetatively modified members of the orchid subtribe Oncidiinae is presented. The make-up and circumscription of the group of species (Table 1) treated here as an example of the application of this clone bank were determined by an overall analysis of vegetative features (Chase, 1986) and micromorphological details of the complex pollinaria (Chase, 1987) in subtribe Oncidiinae. Most species in subtribe Oncidiinae have been shown to be $2 n=56$ (Tanaka and Kamemoto, 1984), while the members of this vegetatively modified group have a range of lower numbers, $2 n=24-44$ (Fig. 5), which have been demonstrated to be derived by aneuploid changes (probably reduction; Chase and Olmstead, 1988). Additionally, a survey of seed morphology of the subtribe (Chase and Pippen, 1988) found a unique sculpturing of the cell walls to be restricted to these same species. A preliminary analysis of cpDNA variation in the subtribe (Chase and Palmer, 1988) was also used to support the naturalness of this clade relative to the rest of the subtribe. While $O$. excavatum is representative of the largest clade of Oncidium $(2 n=56$ and the conserved type section; Dressler and Williams, 1982; Brummit, 1985), Rossioglossum $(2 n=44)$ appears to be a more closely related taxon that would perhaps permit a more accurate assessment of polarity of the mutations found in this group. Indeed, a number of authors (Wirth, 1964; Dressler and Williams, 1982; Dressler, 1981) have suggested it as a close outlier to the vegetatively modified group. When considered from the perspective of Garay and Stacy's sectional revision of Oncidium (1974), this group of species would appear to be almost randomly chosen (Table 4), but the abundant evidence cited above suggested that these nine species (exclusive of Trichocentrum) were a monophyletic unit. The exact relationship of Trichocentrum to this vegetatively modified clade was the point of contention and the focus of this example.

The cpDNA data clearly support neither previously suggested hypothesis: Trichocentrum is not an associated, monophyletic, outlier relative to the others or a sister group to the mule ear clade, but rather a closely related derivative of the larger vegetatively modified lineage. In the preliminary molecular analysis of Chase and Palmer (1988), no other members of the Oncidiinae fell within this clade, although sev- 
TABLE 4. Subgeneric and sectional assignments in Oncidium (Garay and Stacy, 1974) of the species from $7 a b l e 1$.

(Taxa marked with an asterisk have not been treated as members of genus Oncidium)

\begin{tabular}{lll}
\hline \hline \multicolumn{1}{c}{ Species and author } & \multicolumn{1}{c}{ Subgenus } & Section \\
\hline Oncidium excavatum Lindley & Oncidium & Excavata \\
* Rossioglossum schlieperianum Reichenb. f. & & \\
Oncidium ampliatum Lindley & Oncidium & Oblongata \\
Psychopsis sanderae (Rolfe) Lückel and Braem & Oncidium & Glanduligera \\
Oncidium jonesianum Reichenb. f. & Oncidium & Cebolletae \\
Oncidium ascendens Lindley & Oncidium & Cebolletae \\
Oncidium flavovirens L. O. Williams & Cyrtochilum & Cyrtochilum \\
Oncidium splendidum A. Rich. & Oncidium & Plurituberculata \\
Oncidium bicallosum Lindley & Oncidium & Plurituberculata \\
*Trichocentrum panduratum Schweinfurth & & \\
*Trichocentrum tigrinum Linden and Reichenb. f. & & Pulvinata \\
Oncidium pulvinatum Lindley & Oncidium & Paucituberculata \\
Oncidium hians Lindley & Oncidium & \\
\hline
\end{tabular}

eral other genera (Cuitlauzina, Lemboglossum, Osmoglossum, Palumbina, and Ticoglossum) appear to be as closely related to this group as Rossioglossum. An analysis of the whole subtribe is underway and will address the relationships more fully. The most that can be concluded on the basis of this analysis is that including the vegetatively modified taxa in $\mathrm{On}$ cidium does not result in monophyletic taxa unless Psychopsis, Rossioglossum, and Trichocentrum are not also included. An already proposed alternative would be the removal of this clade from Oncidium as genus Lophiaris (Dressler, 1981, prudently did not make any formal transfers). Such taxonomic decisions should not be contemplated in isolation, but rather be a part of a comprehensive generic revision of the Oncidiinae (approximately 1,500 species in 75 poorly delineated genera). The focus of this smaller study was the position of Trichocentrum, and an hypothesis of close, derivative relationship has been supported.

The Orchidaceae, and the Oncidiinae in particular, are known from the horticultural literature as a group in which few barriers to hybridization exist, and this introduces a question as to whether Trichocentrum might not have originated as a hybrid between a mule ear type and another member of subtribe Oncidiinae. If the female parent had been a member of the former type, then the hybrid would exhibit a chloroplast genome typical of this group. We offer several points to counter such an explanation. Documented hybrids from nature are rare in the Oncidiinae (MWC, personal observation); this is due, we believe, to the fact that relationships with specific pollinators rarely break down (natural barriers to hybridization are mechanical, not physiological or genetic). More importantly and specific to this case, Trichocentrum is an extreme example of vegetative and floral modification, not an intermediate as one would expect in a hybrid. Additionally, the chromosome numbers found in this clade (discussed in more detail below) exhibit a definite trend, and Trichocentrum occupies its lowest point.

Aneuploid change in chromosome number is a major feature of several groups within the Oncidiinae (Chase, 1986; Chase and Olmstead, 1988). Chase (1986) hypothesized that the morphological evidence was compatible with aneuploid reduction: progressively lower numbers were associated with increasingly modified vegetative features. Diploid chromosome numbers have been added to Fig. 5, and the result is clearly compatible with an hypothesis that aneuploid decreases are responsible for the variation in chromosome number in this clade.

Most orchid subtribes are relatively uniform in nonfloral aspects. The Oncidiinae, in contrast, is one of the most diverse in the family from cytological, ecological, and morphological (both floral and vegetative) standpoints (Dressler, 1981). For example, the range of chromosome number in this subtribe, $2 n=$ $10-60$, exceeds that of the rest of the family. In their taxonomy, gross floral morphology has been emphasized, and often, in cases in which the floral and vegetative features lead to vastly different generic limits, the ones based on the latter have been disregarded. The resulting generic treatments of all but the most recent authors have been totally artificial. Garay and Stacy's (1974) arrangement of the sections of Oncidium was by their own admissions artificial, i.e., closely related species were often placed in different sections. The eleven species of the ingroup in this study were placed in seven sections, in each of the two subgenera of $\mathrm{On}$ cidium (Table 4), as well as in Psychopsis and Trichocentrum. This disassociation of taxa so 
well circumscribed by their distinctive vegetative features, as well as their much lower chromosome numbers, is a result of the supremacy of gross floral features in taxonomic matters.

We suspect that the problem illustrated by this study is not an isolated case in the Orchidaceae (and in many other flowering plant families, as well). Apparently rapid, drastic alteration of floral morphology has long been suggested as a major factor in the evolution of the family (Dodson, 1962). If the overall genetic basis is as equally minor as the differences in cpDNA, then the floral differences that characterize Trichocentrum and $O$. bicallosum may result from relatively few alterations in the gene(s) that control gross floral features. If this is a model for orchids in general (and we intend to test this hypothesis by genetic studies examining the transmission of floral types), then gross floral morphology cannot be trusted to lead us to accurate phylogenetic hypotheses. This has an ominous portent for a family in which floral morphology has been so heavily emphasized.

The application of molecular data to phylogenetic programs in the Orchidaceae and other lilioid monocot families has been lagging behind that of similar studies in the dicots. The orchid clone bank described in this paper is a major step in fostering the practicality of studies similar to the one reported here that have a fairly narrow (interspecific, intergeneric) focus. One of the major phylogenetic problems facing systematists is that of interfamilial relationships, which in general cannot be dealt with by comparative restriction site mapping (Palmer et al., 1988a). The chloroplast genomes of the three different groups traditionally recognized as members of the Liliaceae sensu lato, while apparently identical in genome arrangement, are probably too different in size for this approach to be used. Sequence data from conserved genes, chloroplast or otherwise, will be needed in order to construct phylogenetic hypotheses for taxa that are divergent in cpDNA size and sequence. Nonetheless, comparative restriction site mapping has added a new dimension to the study of infrafamilial relationships in the Orchidaceae. The evidence from several recent studies focused on the Oncidiinae supported the position of Dressler and Williams (1982) that Trichocentrum is closely related to the vegetatively modified members of Oncidium. The grossly different floral morphology of Trichocentrum suggests no derivative relationship from that of Oncidium, and its modified habit only places it in affinity with this group. Few workers had been convinced that vegetative features offered a more reliable basis for generic circumscription. The evidence from analysis of cpDNA has dramatically presented us with an hypothesis of a previously unsuspected degree of plasticity in floral morphology and casts suspicion on evolutionary hypotheses that do not utilize all features of these plants.

\section{LITERATURE CITED}

Brummit, R. K. 1985. Report of the committee for the Spermatophyta, 679. Taxon 34: 661 .

Chase, M. W. 1986. A reappraisal of the oncidioid orchids. Syst. Bot. 11: 477-491.

- 1987. Systematic implications of pollinarium morphology in Oncidium Sw., Odontoglossum Kunth, and allied genera (Orchidaceae). Lindleyana 2: 8-28.

- - AND R. G. Olmstead. 1988. Isozyme number in subtribe Oncidiinae (Orchidaceae): an evaluation of polyploidy. Amer. J. Bot. 75: 1080-1085.

- $\longrightarrow$ AND J. D. PAlmer. 1988. Chloroplast DNA variation, geographical distribution, and morphological parallelism in subtribe Oncidiinae (Orchidaceae). Amer. J. Bot. 75: 163-164.

- AND J. S. PIPPEN. 1988. Seed morphology in the Oncidiinae and related subtribes (Orchidaceae). Syst. Bot. 13: 313-323.

de HeIJ, H. T., H. Lustig, D. M. Moeskops, W. A. BovenBerg, C. Bisanz, and G. S. P. Groot. 1983. Chloroplast DNAs of Spinacia, Petunia, and Spirodela have a similar gene organization. Curr. Genet. 7: $1-6$.

DoDson, C. H. 1962. The importance of pollination in the evolution of the orchids of tropical America. Amer. Orchid. Soc. Bull. 31: 525-534, 641-649, 731-735.

Doebley, J., W. Renfroe, AND A. Blanton. 1987. Restriction site variation in the Zea chloroplast genome. Genetics 117: 139-147.

Doyle, J. J., AND J. L. DoYle. 1987. A rapid DNA isolation procedure for small quantities of fresh leaf tissue. Phytochem. Bull. 19: 11-15.

DRESSLER, R. L. 1981. The orchids: natural history and classification. Harvard University Press, Cambridge.

, AND N. H. Williams. 1982. Proposal for the conservation of the generic name 1779 Oncidium Swartz (Orchidaceae) with a conserved type species, Oncidium altissimum Sw. Taxon 31: 752-754.

Enomoto, S. Y., Y. Ogihara, And K. Tsunewaki. 1985. Studies on the origins of crop species by restriction endonuclease analysis of organellar DNA. I. Phylogenetic relationships among ten cereals revealed by the restriction fragment patterns of chloroplast DNA. Jap. J. Genet. 60: 411-424.

Felsenstein, J. 1985. Confidence limits on phylogenies: an approach using the bootstrap. Evolution $39: 783$ 791.

Garay. L. A., And J. E. Stacy. 1974. Synopsis of the genus Oncidium. Bradea 1: 393-428.

Hilu, K. W. 1988. Chloroplast DNA in the systematics and evolution of the Poaceae. In T. R. Soderstrom, K. W. Hilu, C. S. Campbell, and M. E. Barkworth [eds.], Grass systematics and evolution, 65-72. Smithsonian Press, Washington, DC.

Howe, C. J., R. F. Barker, C. N. Bowman, and T. A. DYER. 1988. Common features of three inversions in wheat chloroplast DNA. Curr. Genet. 13: 343-349. 
JANSEN, R. K., AND J. D. PAlmer. 1987. Chloroplast DNA from lettuce and Barnadesia (Asteraceae): structure, gene localization and characterization of a large inversion. Curr. Genet. 11: 553-564.

- AND - 1988. Phylogenetic implications of chloroplast DNA restriction site variation in the $\mathrm{Mu}-$ tisieae (Asteraceae). Amer. J. Bot. 75: 753-766.

Lehvaslaiho, H., A. Saura, AND J. LoKku. 1987. Chloroplast DNA variation in the grass tribe Festuceae. Theor. Appl. Genet. 74: 298-302.

Marsh. J. L., M. Erfle, and E. J. Wilkes. 1984. The pIC plasmid and phage vectors with versatile cloning sites for recombinant selection by insertional inactivation. Gene 32: 481-485.

NeI, M., AND W. LI. 1979. Mathematical models for studying genetic variation in terms of restriction endonucleases. Proc. Natl. Acad. Sci. USA 76: 52695273.

PALMER, J. D. 1985. Comparative organization of chloroplast genomes. Annual Rev. Genet. 19: 325-354. 1986. Isolation and structural analysis of chloroplast DNA. Meth. Enzymol. 118: 167-186.

, R. K. Jansen, H. J. Michaels, M. W. Chase, and J. R. MANHART. 1988a. Chloroplast DNA variation and plant phylogeny. Ann. Missouri Bot. Gard. 75: 1180-1206.

- B. OSARIO, AND W. F. Thompson. 1988b. Evolutionary significance of inversions in legume chloroplast DNAs. Curr. Genet. 14: 65-74.

- C. R. Shields, D. B. Cohen, And T. J. Orton.
1983. Chloroplast DNA evolution and the origin of amphidiploid Brassica. Theor. Appl. Genet. 65: $181-$ 189.

, AND W. F. THOMPSON. 1981. Clone banks of mung bean, pea, and spinach chloroplast DNA. Gene 15: $21-26$

- AND D. ZAMIR. 1982. Chloroplast DNA evolution and phylogenetic relationships in Lycopersicon. Proc. Natl. Acad. Sci. USA 79: 5006-5010.

Sytsma, K. J., ANd L. D. Gottlieb. 1986. Chloroplast DNA evolution and phylogenetic relationships in Clarkia sect. Peripetasma (Onagraceae). Evolution 40: 1248-1262.

, AND B. A. SChaAl. 1985. Phylogenetics of the Lisianthus skinneri (Gentianaceae) species complex in Panama using DNA restriction fragment analysis. Evolution 39: 594-608.

TANAKA, R., AND K. Kamemoto. 1984. Chromosomes in orchids: counting and numbers. In J. Arditti [ed.], Orchid biology: reviews and perspectives, III, 321410. Cornell University Press, Ithaca, NY.

TSUNEWAKI, K., AND Y. OGIHARA, 1983. The molecular basis of genetic diversity among cytoplasms of Triticum and Aegilops species. II. On the origin of polyploid wheat cytoplasms as suggested by chloroplast DNA restriction fragment patterns. Genetics 104: 155171.

WIRTH, M. 1964. Supraspecific variation and classification in the Oncidiinae (Orchidaceae). Ph.D. dissertation, Washington University, St. Louis, MO. 